Research Paper

\title{
Current Situation of Nutritional Care in Children Under 6 Months of Age at the Vietnam National Children's Hospital in 2019
}

\author{
Nguyen Van Nhien ${ }^{1,}$, Luu Thi My Thuc ${ }^{2}$, Le Thi $\mathrm{Ha}^{2}$, Phan Thi $\mathrm{Nga}^{2}$ \\ ${ }^{I}$ Vinh Phuc Obsetric and Pediatric Hospital, 349 Me Linh, Khai Quang, Vinh Yen, Vinh Phuc, Vietnam \\ ${ }^{2}$ Vietnam National Children's Hospital, 18/879 La Thanh, Dong Da, Hanoi, Vietnam
}

Received 26 March 2020

Revised 02 April 2020; Accepted 20 April 2020

\begin{abstract}
Objectives: To describe epidemiological characteristics, methods of care, the level of physical development of children under 6 months of age to come to the Nutrition Clinic, Vietnam National Children's Hospital in 2019.

Subject: Mothers and children $<6$ months old visited the National Children's Hospital for the first time from January 2019 to December 2019. Research methodology: crosssectional description.

Results and conclusions: $18.7 \%$ of infants were exclusively breastfed for the first 6 months, $45.6 \%$ of infants were given early solids. $48.6 \%$ of children use formula milk because mothers did not have enough milk, $30.6 \%$ because mothers had to go to work early. $98.9 \%$ of mothers and grandmothers prepare baby food, however $58.3 \%$ did not follow the proper methods. $52.9 \%$ of babies were breastfed $<1$ hour after delivery, $41.0 \%$ of mothers knew how to breastfeed properly.
\end{abstract}

Keywords: Nutritional care, children under 6 months.

\footnotetext{
Corresponding author.

E-mail address: nvn@gmail.com

https://doi.org/10.25073/ jprp.v4i2.217
} 


\title{
Thực trạng chăm sóc dinh dưỡng ở trẻ dưới 6 tháng tuổi tại Bệnh viện Nhi Trung ương năm 2019
}

\author{
Nguyễn Văn Nhiên ${ }^{1, *}$, Lưu Thị Mỹ Thục ${ }^{2}$, Lê Thị Hà ${ }^{2}$ Phan Thị Nga ${ }^{2}$ \\ ${ }^{I}$ Bệnh viện Sản Nhi Vĩnh Phúc, Số 349 Mê Linh, Khai Quang, Vĩnh Yên, Vĩnh Phúc, Việt Nam \\ ${ }^{2}$ Bệnh viện Nhi Trung uoong, 18/879 La Thành, Đống Đa, Hà Nội, Việt Nam \\ Nhận ngày 26 tháng 3 năm 2020 \\ Chỉnh sửa ngày 02 tháng 4 năm 2020; Chấp nhận đăng ngày 20 tháng 4 năm 2020
}

\section{Tóm tắt}

Mục tiêu: Mô tả đặc điểm dịch tễ học, phương pháp chăm sóc, mức độ phát triển thể chất của trẻ dưới 6 tháng tuổi đến khám tại phòng khám dinh dưỡng bệnh viện Nhi Trung ương năm 2019.

Đối tượng: Bà mẹ và trẻ <6 tháng tuổi đến khám lần đầu tại Bệnh viện Nhi Trung ương từ tháng $1 / 2019$ đến 12/2019.

Phương pháp nghiên cứu: mô tả cắt ngang.

Kết quả và kết luận: $18,7 \%$ trẻ được nuôi hoàn toàn bằng sữa mẹ trong 6 tháng đầu, 45,6\% trẻ ăn dặm sớm. 48,6\% trẻ sử dụng sữa công thức là do mẹ không đủ sữa, 30,6\% do mẹ phải đi làm sớm. $98,9 \%$ mẹ và bà là người chế biến đồ ăn dặm cho trẻ, tuy nhiên $58,3 \%$ chế biến chưa đúng phương pháp. $52,9 \%$ trẻ được bú $<1$ giờ sau đẻ, $41,0 \%$ bà mẹ biết cho bú đúng cách.

Tù khóa: Chăm sóc dinh dưỡng, trẻ dưới 6 tháng.

\section{1. Đặt vấn đề}

Dinh dưỡng vô cùng quan trọng đối với cuộc sống của mỗi người đặc biệt là trẻ em. Với trẻ nhỏ, sữa mẹ là một phần không thể thiếu, nhất là 6 tháng đầu sau sinh [1],[2]. Tuy nhiên không phải ai cũng hiểu được những giá trị mà sữa mẹ mang lại cũng như biết cho ăn ăn đúng cách. Với sự phát triển kinh tế xã hội hiện nay, các bà mẹ thường phải đi làm từ sớm hay chương trình quảng cáo về các loại sữa thay thế khiến cho trẻ không được bú mẹ hoàn toàn. Từ đó ảnh hưởng không nhỏ tới tình trạng dinh dưỡng của trẻ. Để tìm hiểu kỹ hơn nhằm phục vụ

*Tác giả liên hệ.

Địa chi email: nvn@gmail.com

https://doi.org/10.25073/ jprp.v4i2.217 công tác chẩn đoán và điều trị dinh dưỡng, chúng tôi thực hiện nghiên cứu nhằm mục tiêu: "Mô tả đặc điểm dịch tễ học, phương pháp chăm sóc, mức độ phát triển thể chất của trẻ dưới 6 tháng tuổi đến khám tại phòng khám dinh dưỡng bệnh viện Nhi Trung ương năm 2019”.

\section{2. Đối tượng và phương pháp nghiên cứu}

2.1. Đối tương, địa điểm và thời gian nghiên cúu

Bà mẹ và trẻ $<6$ tháng tuổi đến khám lần đầu tại Bệnh viện Nhi Trung ương từ tháng $1 / 2019$ đến $12 / 2019$.

\subsection{Phương pháp nghiên cứu}




\subsubsection{Thiết kế nghiên cứu}

Mô tả cắt ngang.

2.2.2. Cỡ mẫu và chọn mẫu nghiên cứu

Tính theo công thức cỡ mẫu ước lượng một tỷ lệ:

$$
n=Z_{(1-\alpha / 2)}^{2} \frac{p \cdot(1-p)}{d^{2}}
$$

Cỡ mẫu nhóm trẻ cần khảo sát: $\mathrm{n}$ là cỡ mẫu tối thiểu cần điều tra, $\alpha$ là ý nghĩa thống kê, ở mức $\alpha=0,05$ giá trị $Z$ tương ứng là $1,96 . \mathrm{p}=0,5$ để đạt cỡ mẫu lớn nhất. $\mathrm{d}$ là sai số mong đợi, lấy $\mathrm{d}=0,05$. Thay vào công thức tính được $\mathrm{n}=384$ trẻ.

Phương pháp chọn mẫu thuận tiện đến khi đủ số mẫu cần nghiên cứu.

2.2.3. Phương pháp thu thập thông tin

Phỏng vấn trực tiếp các bà mẹ qua phiếu điều tra và khám lâm sàng trẻ

\subsubsection{Xử lý số liệu}

Số liệu được nhập và xử lý bằng phần mềm thống kê SPSS 20.0.

\section{Kết quả nghiên cứu và bàn luận}

Thông qua nghiên cứu 384 trẻ, chúng tôi thu được kết quả như sau:

Bảng 3.1. Đặc điểm chung của đối tượng nghiên cứu

\begin{tabular}{|l|l|l|}
\hline Đặc điểm & $\begin{array}{l}\text { Số lượng } \\
(\mathrm{n}=384)\end{array}$ & Tỷ lệ \% \\
\hline Con đầu lòng & 241 & 62,8 \\
\hline Đẻ thường & 233 & 60,7 \\
\hline Đủ tháng & 356 & 92,7 \\
\hline Đủ cân & 348 & 90,6 \\
\hline Trẻ nam & 204 & 53,1 \\
\hline Trẻ nữ & 180 & 46,9 \\
\hline
\end{tabular}

Kết quả Bảng 3.1 cho thấy trên $60 \%$ trẻ là con đầu lòng và được đẻ thường; trên
$90 \%$ trẻ đủ cân đủ tháng. Trẻ có giới tính nam nhiều hơn so với nữ $(53,1 \%$ so với $46,8 \%)$. Kết quả này phù hợp với nhiều nghiên cứu trong nước khác của Trần Thị Hoài Phương [1], Nguyễn Thị Lâm [2] và Trần Thị Thanh Tâm [3].

Bảng 3.2. Lý do đến khám của đối tượng nghiên cứu

\begin{tabular}{|l|l|l|}
\hline Lý do đến khám & $\begin{array}{l}\text { Số lượng } \\
(\mathrm{n}=384)\end{array}$ & Tỷ lệ\% \\
\hline Nôn trớ & 28 & 7,3 \\
\hline Vặn mình khó ngủ & 21 & 5,5 \\
\hline Biếng ăn & 122 & 31,8 \\
\hline Chậm lên cân & 102 & 26,6 \\
\hline Bệnh lý cấp tính & 116 & 30,2 \\
\hline
\end{tabular}

Các trẻ được đưa đi khám vì nhiều lý do, trong đó chiếm tỷ lệ cao nhất là biếng ăn với $31,8 \%$, thấp hơn là bệnh lý cấp tính $30,2 \%$, chậm lên cân $26,6 \%$. Trần Thị Hoài Phương nghiên cứu tại bệnh viện nhi đồng 2 và Dewey trong nghiên cứu về tác dụng của sữa mẹ trên trẻ sơ sinh [4] cũng cho tỷ lệ tương đồng với nghiên cứu của chúng tôi [1]. Có thể thấy, đây là những lý do phổ biến ở trẻ nói chung, không phụ thuộc vùng miền.

Bảng 3.3. Phương pháp nuôi dưỡng trẻ

\begin{tabular}{|l|l|l|}
\hline $\begin{array}{l}\text { Phương pháp nuôi } \\
\text { dưỡng }\end{array}$ & $\begin{array}{l}\text { Số lượng } \\
(\mathrm{n}=384)\end{array}$ & Tỷ lệ \% \\
\hline Sữa mẹ & 72 & 18,7 \\
\hline Sữa công thức & 53 & 13,8 \\
\hline $\begin{array}{l}\text { Sữa mẹ + Sữa công } \\
\text { thức }\end{array}$ & 84 & 21,9 \\
\hline Sữa + Ăn dặm & 175 & 45,6 \\
\hline
\end{tabular}

Tỷ lệ bà mẹ cho con ăn sữa mẹ trong 6 tháng đầu tương đối thấp với $18,7 \%$. Kết 
quả này trong nghiên cứu của chúng tôi cao hơn so với Trần Thị Hoài Phương (17,9\%) và kết quả của UNICEF (17,0\%). Chúng tôi cho rằng do sự khác biệt về khoảng thời gian nghiên cứu cũng như địa dư. Hiện nay, với sự giúp đỡ của truyền thông, các bà mẹ đã biết nhiều hơn về lợi ích của sữa mẹ.

Tỷ lệ ăn dặm sớm tương đối cao với $45,6 \%$, sử dụng cả sữa mẹ và sữa công thức là $21,9 \%$. Việc cho trẻ ăn những nguồn thức ăn ngoài sữa mẹ trong 6 tháng đầu là không được khuyến cáo. Tuy nhiên, có nhiều lý do dẫn đến điều đó, có thể do các bà mẹ không đủ sữa hoặc do phải đi làm sớm, không đủ khả năng để duy trì liên tục sữa mẹ cho con.

Bảng 3.4. Thực trạng nuôi con bằng sữa mẹ

\begin{tabular}{|c|c|c|c|}
\hline \multicolumn{2}{|l|}{ Đặc điểm } & $\begin{array}{l}\text { Số } \\
\text { lượng }\end{array}$ & Tỷ lệ \% \\
\hline \multirow{2}{*}{$\begin{array}{l}\text { Thời } \\
\text { điểm } \\
\text { dùng }\end{array}$} & $\begin{array}{l}\text { Sau đẻ <1 } \\
\text { giờ }\end{array}$ & 203 & 52,9 \\
\hline & $\begin{array}{l}\text { Sau đẻ } \geq 1 \\
\text { giờ }\end{array}$ & 181 & 47,1 \\
\hline \multirow{3}{*}{$\begin{array}{l}\text { Phương } \\
\text { thức cho } \\
\text { bú }\end{array}$} & $\begin{array}{l}\text { Bú cạn } 1 \\
\text { bên }\end{array}$ & 196 & 41,0 \\
\hline & $\begin{array}{l}\text { Bú đều } 2 \\
\text { bên }\end{array}$ & 125 & 32,6 \\
\hline & $\begin{array}{l}\text { Bú không } \\
\text { hết } 1 \text { bên }\end{array}$ & 63 & 16,4 \\
\hline
\end{tabular}

Kết quả bảng 3.4 cho thấy có $52,9 \%$ bà mẹ cho con bú $<1$ giờ sau đẻ. Tỷ lệ này cao hơn so với 9 năm trước đây là 46,0\% [1]. Chúng tôi cho rằng đây là kết quả của truyền thông tốt về lợi ích của sữa non. Có $41,0 \%$ bà mẹ biết nên cho bú cạn 1 bên, tuy nhiên vẫn còn $32,6 \%$ bà mẹ cho bú đều 2 bên và $16,4 \%$ bú không hết. Bú không đúng cách có thể để lại nhiều tác hại không tốt cho bà mẹ. Đây là một vấn đề mà truyền thông $\mathrm{y}$ tế cần quan tâm hơn nữa.
Bảng 3.5. Thực trạng nuôi con bằng sữa công thức

\begin{tabular}{|c|c|c|c|}
\hline \multicolumn{2}{|c|}{ Đặc điểm } & $\begin{array}{l}\text { Số } \\
\text { lượng }\end{array}$ & $\begin{array}{l}\text { Tỷ lệ } \\
\%\end{array}$ \\
\hline \multirow{3}{*}{$\begin{array}{l}\text { Thời } \\
\text { điểm } \\
\text { dùng }\end{array}$} & $\begin{array}{l}\text { Trẻ <1 } \\
\text { tháng }\end{array}$ & 48 & 66,7 \\
\hline & $\begin{array}{l}\text { Trẻ } 1 \text { - <4 } \\
\text { tháng }\end{array}$ & 22 & 30,5 \\
\hline & $\begin{array}{l}\text { Trẻ } 4 \text { - <6 } \\
\text { tháng }\end{array}$ & 2 & 2,8 \\
\hline \multirow{4}{*}{$\begin{array}{l}\text { Lý do } \\
\text { nuôi }\end{array}$} & $\begin{array}{l}\text { Mẹ không } \\
\text { đủ sữa }\end{array}$ & 35 & 48,6 \\
\hline & $\begin{array}{l}\text { Mẹ phải đi } \\
\text { làm sớm }\end{array}$ & 22 & 30,6 \\
\hline & Khác & 13 & 18,0 \\
\hline & $\begin{array}{l}\text { Ý kiến gia } \\
\text { đình }\end{array}$ & 2 & 2,8 \\
\hline
\end{tabular}

Bảng 3.5 cho thấy trong số các trẻ ăn sữa công thức, $2 / 3$ số trẻ được cho ăn từ $<1$ tháng, một phần lý do ở đây là do bà mẹ không đủ sữa $(48,6 \%)$ và phải đi làm sớm $(30,6 \%)$. So sánh với nghiên cứu của Trần Thị Hoài Phương, kết quả của chúng tôi cho ra tỷ lệ khác biệt. Trần Thị Hoài Phương ghi nhận tỷ lệ ăn sữa công thức trong tháng đầu tiên là $72,0 \%$, bà mẹ không đủ sữa là $44,0 \%$ và bà mẹ đi làm sớm là $19,0 \%[1]$.

Bảng 3.6. Thực trạng ăn bổ sung của trẻ

\begin{tabular}{|l|l|l|l|}
\hline \multirow{2}{*}{ Đặc điểm } & $\begin{array}{l}\text { Số } \\
\text { lượng }\end{array}$ & $\begin{array}{l}\text { Tỷ lệ } \\
\%\end{array}$ \\
\hline \multirow{2}{*}{$\begin{array}{l}\text { Thời } \\
\text { điềm } \\
\text { dùng }\end{array}$} & $\begin{array}{l}\text { Trẻ 3 - <4 } \\
\text { tháng }\end{array}$ & 118 & 67,4 \\
\cline { 2 - 4 } & $\begin{array}{l}\text { Trẻ 4 - <6 } \\
\text { tháng }\end{array}$ & 57 & 32,6 \\
\hline \multirow{2}{*}{$\begin{array}{l}\text { Người } \\
\text { chế biến }\end{array}$} & Mẹ & 157 & 89,7 \\
\cline { 2 - 4 } & Bà & 16 & 9,2 \\
\cline { 2 - 4 } & Khác & 2 & 1,1 \\
\hline \multirow{2}{*}{$\begin{array}{l}\text { Phương } \\
\text { pháp chế } \\
\text { biến }\end{array}$} & Đúng cách & 73 & 41,7 \\
\cline { 2 - 4 } & $\begin{array}{l}\text { Không } \\
\text { đúng }\end{array}$ & 102 & 58,3 \\
\hline
\end{tabular}


Trong số các trẻ được ăn dặm thì 67,4\% ăn trong khoảng 3-4 tháng tuổi. 32,6\% ăn trong khoảng 4-6 tháng tuổi, những trẻ này chưa tuân thủ theo khuyến cáo ăn dặm từ trên 6 tháng hiện nay. Có thể lý giải bởi ảnh hưởng của yếu tố thiếu sữa của mẹ và việc các bà mẹ phải đi làm sớm do đó không có điều kiện cho ăn ăn theo hướng dẫn.Thực ăn cho trẻ đa phần do mẹ và bà chế biến tuy nhiên có tới $58,3 \%$ chế biến không đúng cách, không đủ 4 nhóm thực phẩm, tỷ lệ các chất chưa cân đối hoặc mua thức ăn chế biến sẵn.

\section{Kết luận}

$18,7 \%$ trẻ được nuôi hoàn toàn bằng sữa mẹ trong 6 tháng đầu, $45,6 \%$ trẻ ăn dặm sớm. $48,6 \%$ trẻ sử dụng sữa công thức là do mẹ không đủ sữa, 30,6\% do mẹ phải đi làm sớm. $98,9 \%$ mẹ và bà là người chế biến đồ ăn dặm cho trẻ, tuy nhiên $58,3 \%$ chế biến chưa đúng phương pháp. $52,9 \%$ trẻ được bú $<1$ giờ sau đẻ, $41,0 \%$ bà mẹ biết cho bú đúng cách.

\section{Tài liệu tham khảo}

[1] Tran Thi Hoai Phuong, Nguyen Thi Kim Hoang, Nguyen Thi Kieu Thu et al. Survey the situation of nutrition care in children under 6 months old to visit the nutrition clinic at the Children's Hospital No. 2, 2008-2009. Journal of Nutrition and Food 2010; 6 (1): 60-65. (In Vietnamese)

[2] Nguyen Thi Lam (2006). Situation of care and nurturing children under 2 years old. Survey data of Nutrition Institute. (in Vietnamese)

[3] Tran Thi Thanh Tam. Breastfeeding Nurturing. Lecture Pediatrics, Hanoi Medical Publishing House 2004: 94-110. (in Vietnamese)

[4] Dewey K.G. Nutrion, growth and complementary feeding of the breastfed infant. Pediatr Clin North Am 2001; 48: 87-104.

[5] Dewey K.G., Heinig M.J., Nommsen L.A et al. Growth of breast-fed and fomula-fed infants from 0-18 months: the darling study. Pediatrics 1992; 89:1035-1041.

[6] Garza C., Butte N.B., Goldman A.S. Human milk and Infant formula. Textbook of Pediatric Nutrion. $2^{\text {nd }}$ ed, 2004:33-42.

[7] Britton H. Mother-Infrant interaction relationship to early infant nutrion and feeding. Textbook of Pediatric Nutrion. $2^{\text {nd }}$ ed. 2004:43-48. 


\section{PHIẾU THU THẬP SỐ LIỆU \\ Thực trạng chăm sóc dinh dưỡng ở trẻ dưới 6 tháng tuổi \\ tại bệnh viện Nhi Trung ương \\ Mã số phiếu:}

1. Họ và tên bệnh nhi:

2. Mã bệnh án:

3. Giới tính: $\quad \square$ Nam $\quad \square$ Nũ̃

4. Tuổi: tháng tuổi.

5. Con đầu lòng: $\quad \square$ Đúng

6. Đẻ thường: $\square$ Đúng

7. Đẻ đủ tháng: $\quad \square$ Đúng

8. Đẻ đủ cân: $\square$ Đúng

$\square$ Sai

9. Lý do đến khám:

$\square$ Nôn trớ $\quad \square$ Vặn mình khó ngủ $\square$ Biếng ăn $\quad \square$ Chậm lên cân $\quad \square$ Bệnh cấp tính 10. Phương pháp nuôi:

$\square$ Sữa mẹ $\quad \square$ Sữa công thức $\quad \square$ Sữa mẹ + công thức $\square$ Sữa + ăn dặm

11. Thời điểm bú sữa mẹ: $\quad \square<1$ giờ sau đẻ $\quad \square>1$ giờ sau đẻ

12. Phương thức cho bú: $\quad \square$ Bú cạn 1 bên $\quad \square$ Bú đều 2 bên $\quad \square$ Bú không hết

13. Thời điểm cho ăn sữa công thức: $\square<1$ tháng $\quad \square$ 1-4 tháng $\quad \square 4-6$ tháng

14. Lý do ăn sữa công thức:

$\square$ Mẹ không đủ sữa

$\square$ Mẹ phải đi làm sớm $\square$ Khác

15. Thời điểm ăn dặm:

$\square$ 3-4 tháng

$\square$ 4-6 tháng

$\square>6$ tháng

Hà Nội, ngày ..... tháng ..... năm 20.....

(Ký và ghi rõ họ tên) 